\title{
Test patterns of yaws antibodies in New Zealand
}

\author{
A. FISCHMAN AND H. MUNDT
}

National Reference Laboratory for Venereal Diseases, Auckland Hospital, Park Road, Auckland 3, New Zealand

Several thousand individuals born in Pacific Islands where yaws is endemic (Western Samoa, Cook, and Niue Islands) have emigrated to New Zealand in recent years. Although the population of New Zealand is nearly 3 million-Europeans and Native Maoris-with no endemic yaws, the numbers of sera giving positive results to treponemal tests in this laboratory in these immigrants with presumed yaws antibodies are about the same as those from people with presumed syphilis. As no serological test differentiates between syphilis and yaws, this poses diagnostic problems. Absence of syphilis has usually been assumed in these Islanders, but distinction may be increasingly difficult in the future. Guthe and Idsöe (1968) have pointed out that after mass campaigns against endemic treponematoses, the children of the new generation are now attaining puberty without the relative cross-immunity from yaws possessed by the previous generation against venereal syphilis; nevertheless, in adult Western Samoans, residual sero-reactivity is still high after the World Health Organization campaign.

Observations of anomalous WR-VDRL patterns in this laboratory, and the high sensitivity of a Reiter protein latex test in presumed yaws (Fischman, 1964) prompted us to investigate whether it is possible to establish a test result pattern in sera with yaws antibodies from yaws endemic territories, different from the pattern in syphilis.

\section{Material and methods}

All sera received for routine examination were tested with the Wassermann reaction and VDRL test. If one or both tests were positive, an FTA-ABS test was performed. After a number of positive test results had been noted in 504 specimens from adult Islanders received in a 6-month period, all positive sera in 200 consecutively received specimens from Islanders, were tested with three additional techniques: a cardiolipin WR, a Reiter protein latex (RPL) test, and a Treponema pallidum haemagglutination (TPHA) test. Thus on these specimens three reagin and three treponemal tests were performed. All the subjects tested were pregnant women. Data on a

Received for publication July 20, 1970 previous history of possible yaws or its treatment were not available. A comparable series of sera from New Zealandborn presumed syphilitics, consecutively received, using as criteria one or more positive STS results and a positive FTA-ABS test, was also tested further with the RPL and TPHA tests.

STS WR with crude antigen (WR) and VDRL cardiolipin slide flocculation were performed as described previously (Fischman, 1964). The cardiolipin complement fixation test (CWR) was performed with Wellcome Maltaner antigen. The sensitivity of these tests was regularly checked with the WHO international standard, adjusting to titres found in Copenhagen (Bentzon and Krag, 1961).

FTA-ABS This was performed as described previously (Beggs, 1967).

TPHA This technique, introduced by Rathlev (1967), was performed with reagents from Fuji Zoki Co., Tokyo, by the method described in the firm's booklet on TPHA antigen.

RPL A slide modification of the tube method (Fischman, 1964) was performed as follows: To $0.15 \mathrm{ml}$. Bacto Difco Latex 0.81 , in a test tube, was added $0.15 \mathrm{ml}$. Reiter protein $\mathrm{CF}$ antigen (Wellcome). After mixing by swirling, $0.4 \mathrm{ml}$. glycine buffer $\mathrm{pH} 8.2$ was added, and the suspension allowed to stand for at least 15 minutes at room temperature. To $0.05 \mathrm{ml}$. of serum (previously inactivated) on a division of a glass plate, 1 drop of the sensitized suspension was added, with a capillary pipette delivering approximately 30 drops per $\mathrm{ml}$. After mixing with an applicator stick, the slide was rotated for 5 minutes at 180 r.p.m. on a mechanical rotator; it was read immediately and again after 5 minutes. Agglutination visibile with the naked eye constituted a positive reaction. The screen test on undiluted serum was classified as weak or strong according to the size of the clump.

\section{Results}

REAGIN TESTS

(1) Yaws

169 sera (33.4 per cent.) gave a positive WR and/or VDRL in sera from 504 Pacific Islanders. Of these $36 \cdot 1$ per cent. had both tests positive, $17 \cdot 1$ per cent. 
had a negative WR and a positive VDRL, and $46 \cdot 8$ per cent. had a positive WR and a negative VDRL.

In the series of 200 sera, where the positive specimens were investigated further, the reagin tests showed a similar distribution. Of the 65 sera positive with at least one STS, a positive WR and negative VDRL occurred in 43.1 per cent., both tests were positive in 38.5 per cent., and VDRL alone was positive in 18.4 per cent. (Table I). Of the WR reactions 29.2 per cent. were weak (haemolysis ranging from 20 to 50 per cent.).

TABLE I Comparison of positive STS in yaws sera

\begin{tabular}{|c|c|c|}
\hline Test results & No. & Per cent. \\
\hline $\begin{array}{l}\text { WR + VDRL - } \\
\text { WR - VDRL + } \\
\text { WR + VDRL + }\end{array}$ & $\begin{array}{l}28 \\
12 \\
25\end{array}$ & $\begin{array}{l}43 \cdot 1 \\
18 \cdot 4 \\
38 \cdot 5\end{array}$ \\
\hline Combined reactivity & 65 & $100 \cdot 0$ \\
\hline
\end{tabular}

In order to see whether high WR reactivity was due to the use of crude WR antigen, a comparison was made with cardiolipin Wassermann. Of the 53 sera giving a positive WR with crude antigen, only 45 reacted with CWR.

The total sensitivity of the WR was thus higher than that of both cardiolipin WR and cardiolipin VDRL (Table II).

TABLE II Sensitivities of six tests in yaws sera with positive STS

\begin{tabular}{|c|c|c|c|c|c|c|}
\hline Tests & $W R$ & $C W R$ & $V D R L$ & $F T A-A B S$ & $R P L$ & $T P H A$ \\
\hline $\begin{array}{l}\text { No. } \\
\text { Per cent. }\end{array}$ & $\begin{array}{l}53 \\
81 \cdot 6\end{array}$ & $\begin{array}{l}45 \\
69 \cdot 3\end{array}$ & $\begin{array}{l}37 \\
56 \cdot 9\end{array}$ & $\begin{array}{l}55 \\
84 \cdot 6\end{array}$ & $\begin{array}{l}56 \\
86 \cdot 1\end{array}$ & $\begin{array}{l}59 \\
90 \cdot 7\end{array}$ \\
\hline
\end{tabular}

\section{(2) Syphilis}

In an unselected series of 100 presumed syphilitics (STS and FTA reactive), only two had a positive WR and a negative VDRL. Both tests were positive in 82 per cent., and the VDRL only in 16 per cent. The total sensitivity of the WR was 84 per cent. as compared with 98 per cent. of the VDRL. The relative sensitivities of the WR and VDRL are the reverse of the results in the yaws sera.

\section{TREPONEMAL TESTS}

\section{(1) Yaws}

The sera of the Pacific Islanders reacting with at least one STS showed sensitivity of the same order for the three treponemal tests, with $86 \cdot 1$ per cent. of sera giving reactive RPL, the FTA-ABS being slightly lower, and the TPHA slightly higher (Table II).

While this is somewhat higher than the WR, none of the treponemal tests alone reached the sensitivity of the combined STS (Tables I and II).

There was no complete agreement between any two treponemal tests. A combination of RPL and TPHA reached the sensitivity of that achieved by the combined STS (Table III). A combination of RPL and FTA-ABS gave a slightly lower sensitivity, reacting with 96.8 per cent. of sera positive with a reagin test. Both the RPL and the FTA-ABS were positive in 73.8 per cent. (48), the RPL alone reacted in 12.3 per cent. (8), and the FTA-ABS alone in $10 \cdot 7$ per cent. (7) of sera.

TABLE III Comparison of RPL and TPHA in yaws sera with reactive $S T S$

\begin{tabular}{lccc}
\hline Test results & No. & Per cent. \\
\cline { 1 - 3 } \cline { 3 - 4 } RPL + TPHA + & 50 & 76.9 \\
RPL + TPHA - & 6 & $9 \cdot 2$ \\
RPL - TPHA + & & 9 & 13.9 \\
RPL - TPHA - & & 0 & 0 \\
\hline Combined reactivity & 65 & 100.0 \\
\hline
\end{tabular}

The FTA-ABS and the TPHA showed the closest agreement with each other, which is to be expected because both are $T$. pallidum antigen tests; both were positive in 84.6 per cent. of sera, but with six sera negative in both tests, the combined sensitivity in relation to STS sensitivity was less satisfactory, not exceeding the reactivity of the TPHA alone $(90 \cdot 7$ per cent.).

The sensitivity of the combination of WR with any one of the treponemal tests was slightly less than that of the combined STS. The combined reactivity of the WR and RPL is shown in Table IV. The combination of WR and TPHA also showed a similar sensitivity, 95.4 per cent. 11.3 per cent. of TPHA test results, 7.5 per cent. of RPL, and 49 per cent. of FTA-ABS were weakly reactive.

TABLE IV Comparison of WR and RPL in yaws sera with reactive $S T S$

\begin{tabular}{|c|c|c|}
\hline Test results & No. & Per cent. \\
\hline $\begin{array}{l}\text { WR + RPL + } \\
\mathbf{W R}+\mathbf{R P L}- \\
\mathbf{W R}-\mathbf{R P L}+ \\
\mathbf{W R}-\mathbf{R P L}-\end{array}$ & $\begin{array}{r}47 \\
6 \\
9 \\
3\end{array}$ & $\begin{array}{r}72 \cdot 3 \\
9 \cdot 2 \\
13 \cdot 9 \\
4 \cdot 6\end{array}$ \\
\hline Combined reactivity & 62 & $95 \cdot 4$ \\
\hline
\end{tabular}

(2) Syphilis

In the syphilitic sera, which included specimens with positive FTA-ABS tests only, all sera had a positive result to the TPHA also, but the sensitivity of the RPL was considerably lower, only 65 per cent. 23 per cent. of FTA-ABS, 13.7 per cent. of TPHA, and 50 per cent. of RPL were weakly reactive. 


\section{Discussion}

With the increasing tendency to disregard the Wassermann reaction in many laboratories and to use the VDRL only as a screening procedure followed by a treponemal test, the relation of WR to VDRL reactions is not usually taken into consideration in the treponemal testing. The finding in this study that the WR is frequently reactive, while the VDRL is negative in immigrant Islanders from yaws-endemic territories suggests that the VDRL test is less sensitive than the WR in detecting residual yaws antibodies. This is in contrast with syphilitic sera where this pattern is infrequent and the VDRL shows higher sensitivity. The performance of both the WR and the VDRL may therefore have a definite though limited differential diagnostic value when a population including some with syphilis and some with residual yaws antibodies is to be tested.

These findings may be of less interest when yaws testing is carried out for a purpose other than differential diagnosis, namely mass epidemiology before and after treatment. When sero-reactivity is steadily decreasing in yaws-endemic territories, more reliance may be placed on treponemal than on VDRL test results (Guthe, 1969).

One cannot extend any conclusions from this study to sero-reactivity in populations living in yawsendemic areas. In a recent study on New Guinea inhabitants, the sensitivity of the CWR was lower than that of the TPI, while VDRL sensitivity was close to that of the TPI, with the TPI as the main reference test (Garner and Hornabrook, 1970). The WR with crude antigen was not included in the comparison. As the present study was limited to pregnant women, this and various unknown ecological factors may have contributed to the reaction pattern.

The cardiolipin Wassermann reaction gave a somewhat lower percentage of positive results. While the sensitivity of this test was still higher than that of the VDRL in yaws sera, crude extract antigen seems more suited to demonstrate residual yaws antibodies. Although most workers prefer to use Cardiolipin WR in syphilis, claiming higher sensitivity and specificity, the use of crude antigen has been retained in this laboratory for several reasons. It was thought that, if two routine STS were performed, one being the cardiolipin flocculation test, it might be advantageous to have crude antigen in the other test, as we are performing the STS not only on syphilitic sera, but in conditions in which BFP reactions are frequent. The sensitivity of selected crude antigens in syphilitic sera compared well with that of CWR antigen in our hands, and specificity had to be decided by a treponemal test in any case.
The findings in yaws sera support the continued use of crude WR antigen for another reason.

In view of the similar sensitivity, shown in this series, of the crude WR and the treponemal tests, it may be said that the WR appears fairly specific for yaws antibodies, but it must be borne in mind that during this investigation treponemal tests were performed only on sera with reactive STS. A few sera with negative results to STS which were tested at random did react with some treponemal tests. It is possible that, if all Islanders including those nonreactive to STS were tested, total reactivity to treponemal tests would be further increased. This will be the subject of further study. On the other hand, not all sera reactive with STS reacted with all treponemal tests. In general a combination of two such tests gave sensitivities similar to those obtained with combined STS.

It appears that if one wishes to screen with one simple test for residual yaws antibodies, the RPL as a single test merits further study. One limitation is the great variability in the sensitivities of Reiter protein antigens. Higher sensitivity with some antigens was obtained previously with syphilis sera using the tube test (Fischman, 1964). In the slide test these antigens were oversensitive in the negative control sera (unpublished). The antigen used in this study was more specific in the controls, but less sensitive for syphilis diagnosis, giving good results in the yaws sera.

As a single non-treponemal test the WR reacted better than the VDRL. For better results at least two tests should be performed, either two treponemal reactions, or one treponemal test and the WR.

A considerable proportion of WR and FTA-ABS reactions were weak. Weakly positive reactors are expected in communities with immigrants from yaws areas (Willcox, 1964). Generally, weaker test results may be encountered in subjects with yaws than in those with syphilis (King and Nicol, 1969). In this study the pattern of reactive WR with nonreactive VDRL, and a weakly reactive FTA-ABS appears to be very common in patients with residual yaws antibodies.

\section{Summary}

33.4 per cent. of sera from 504 pregnant Pacific Islanders, born in yaws-endemic territories but now residing in New Zealand were reactive with the Wassermann reaction and VDRL tests, presumably because of residual yaws antibodies.

The WR with crude extract antigen was more reactive than a cardiolipin WR and the VDRL. The pattern of reactive WR, negative VDRL, and weakly- 
reactive FTA-ABS was frequent. This pattern of test results may have a limited differential diagnostic value in examining a community of Europeans and native Maoris, with no yaws, together with immigrants from yaws-endemic territories. In a group of syphilitics, the opposite pattern of results was observed with a higher sensitivity of VDRL.

Three treponemal tests, the FTA-ABS, the slide Reiter protein latex test, and the Treponema pallidum haemagglutination test performed on yaws sera reactive with at least one STS, showed a reactivity ranging from 84.6 to 90.7 per cent., slightly above that of the Wassermann reaction ( 81.3 per cent). The Reiter protein latex test merits further trial as a simple screening treponemal test. Higher sensitivity is obtained by a combination of two tests, either the WR and one treponemal test, or two treponemal tests. Of any two treponemal tests, the combination of the Reiter protein latex and the $T$. pallidum haemagglutination tests gave the highest reactivity.

We are indebted to David Bree for performing some of the FTA-ABS tests.

\section{References}

BEGGS, W. A. (1967) N.Z.F. med. Lab. Tech., 21, 88

Bentzon, M. W., and KRAG, P. (1961) Bull. Wld Hlth Org., 24, 257

Fischman, A. (1964) Brit. f. vener. Dis., 40, 225

GARNER, M. F., and HorNabrook, R. W. (1970) Ibid., 46, 13

GuTHE, T. (1969) Acta derm.-venereol. (Stockh.), 49, 343

- and IDSøE, O. (1968) Brit. F. vener. Dis., 44, 35

KING, A., and Nicol, C. (1969) "Venereal Diseases", 2nd ed., p. 255. Baillière, Tindall, and Cassell, London

Rathlev, T. (1967) Brit. F. vener. Dis., 43, 181
WILlCox, R. R. (1964) "Textbook of Venereal Diseases and Treponematoses," 2nd ed., p. 414. Heinemann, London.

Types de réponses dans la recherche des anticorps pianiques en Nouvelle Zélande SOMMAIRE

Pour 504 femmes enceintes des Iles du Pacifique, nées dans des territoires où le pian est endémique mais résidant maintenant en Nouvelle Zélande, 33.4 pour cent des sérums se montrèrent positifs à la réaction de Wassermann et au VDRL, probablement à cause de la présence d'anticorps pianiques résiduels.

Le $B W$ avec l'antigène extractif brut fut plus positif que le $\mathrm{BW}$ à la cardiolipine et que le VDRL. La réponse: BW positif, VDRL négatif et FTA-ABS faiblement positif fut rencontrée fréquemment. Ce type de réponse peut avoir une certaine valeur diagnostique différentielle lors de l'examen d'Européens et d'indigènes Maoris-nonpianiques-par rapport à l'examen d'immigrants venant de territoires où le pian est endémique. Dans un groupe de syphilitiques, le type de réponse fut inversé, avec une plus grande sensibilité du VDRL.

Trois tests tréponémiques: le FTA-ABS, l'épreuve sur lame au latex avec la proteine de Reiter, et le test d'hémaglutination au Treponema pallidum furent effectués sur des sérums pianiques positifs à au moins une épreuve d'un test standard réaginique; ils montrèrent une positivité de 84,6 à 90,7 pour cent, légèrement supérieur à la réponse du Wassermann (81,3 pour cent). L'épreuve au latex avec l'antigène protéinique Reiter mérite des essais ultérieurs, en tant qu'épreuve tréponémique simple de dépistagz. La plus grande positivité est obtenue par l'association de 2 épreuves: soit le BW et une épreuve tréponémique, soit deux épreuves tréponémiques. Parmi les couples d'épréuves tréponémiques, l'association de la réaction au latex avec l'antigène protéïnique Reiter et de l'hémaglutination du $T$. pallidum donne le plus haut niveau de réactivité. 